University of St. Thomas, Minnesota

UST Research Online

$3-2004$

\title{
I Was Pleased a Moment Ago: How Pleasure Varies With Background and Foreground Reference Points
}

James E. Heyman

jeheyman@stthomas.edu

Barbara Mellers

University of Pennsylvania, mellers@wharton.upenn.edu

Follow this and additional works at: https://ir.stthomas.edu/ocbmktgpub

Part of the Marketing Commons

This Article is brought to you for free and open access by the Marketing at UST Research Online. It has been accepted for inclusion in Marketing Faculty Publications by an authorized administrator of UST Research Online. For more information, please contact asle4660@stthomas.edu. 


\title{
I Was Pleased a Moment Ago: How Pleasure Varies With Background and Foreground Reference Points
}

\author{
James Heyman, ${ }^{1,4}$ Barbara Mellers, ${ }^{1}$ Sergei Tishcenko, ${ }^{2}$ and Alan Schwartz ${ }^{3}$
}

The pleasure of an outcome is often evaluated relative to salient reference points. In the background, increasing sequences of positive outcomes are more enjoyable than decreasing sequences. In the foreground, outcomes that could have been worse are often more enjoyable than those that could have been better. How does pleasure vary when both background and foreground reference points are salient? Using a repeated gambling task in which participants make a choice, learn the outcome, watch their cumulative earnings change, and rate the pleasure of the outcome, we explore this question. Pleasure depends on background and foreground reference points, but the immediate events tend to dominate. The relatively narrow focus on the most recent reference points leads to myopic pleasure. We offer a modified version of decision affect theory to account for the results and explore the implications for consumer satisfaction.

KEY WORDS: pleasure; consumer choice; emotions; reference points; counterfactuals.

Consumer choice is often described as a multiphase process of prepurchase anticipation, decision making, and postpurchase evaluation. Customers with positive anticipated feelings about a product are more likely than customers with neutral or negative feelings to purchase that product. Likewise, customers who are happy using a product are more likely than customers who are neutral or unhappy to purchase the product again (Dabholkar, 1994). The classic and still dominant approach to customer satisfaction is expectancy disconfirmation. In this framework, satisfaction is the difference between prepurchase expectations and postpurchase

\footnotetext{
${ }^{1}$ University of California at Berkeley, Berkeley, California.

${ }^{2}$ Bank of America Capital Management, New York, New York.

${ }^{3}$ University of Illinois, Chicago Circle, Chicago, Illinois.

${ }^{4}$ Address all correspondence to James Heyman, Haas School of Business, University of California at Berkeley, Berkeley, California 94720-1900; e-mail: jheyman@ haas.berkeley.edu.
} 


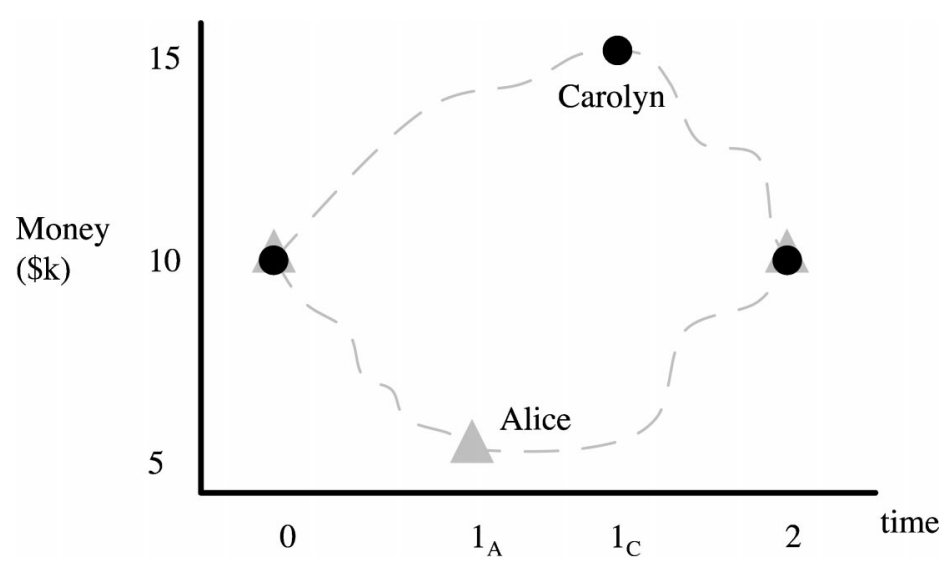

Fig. 1. An illustration of the Alice and Carolyn problem.

experiences (Erevelles \& Leavitt, 1992). Both expectations and experiences depend on reference points, such as a product's positive attributes (Boulding, Kalra, Staelin, \& Zeithaml, 1993), product idealizations (Westbrook, 1987), price-based value expectations (Oliver \& Swan, 1989), experienced-based norms (Cadotte, Woodruff, \& Jenkins, 1987), and social implications (Fournier \& Mick, 1999). The challenge is knowing which reference points will be invoked for any given product at any given time (Iacobucci, Grayson, \& Ostrom, 1994).

The effects of reference points on satisfaction and hedonic experiences are ubiquitous. Psychologists have demonstrated that reference points arise from personal goals, desires, social comparisons, or counterfactual comparisons (Heath, Larrick, \& Wu, 1999; Kahneman \& Miller, 1986; Lopes, 1987; Markman, Gavanski, Sherman, \& McMullen, 1993; Roese \& Olson, 1995; Tesser, 1999). Furthermore, reference points are dynamic, as in the following problem:

At the beginning of the year, Alice invested $\$ 10,000$ in the market. Her investments shrank to $\$ 5,000$, but returned to $\$ 10,000$ by the end of the year. Carolyn also invested $\$ 10,000$. During the same period, her investments grew to $\$ 15,000$ and returned to $\$ 10,000$. Who felt happier at the end of the year?

We asked 145 undergraduates this question as part of broader survey on decision making. Respondents could answer "Carolyn," "Alice," or "They are equally happy." Figure 1 illustrates the question and allows us to introduce some terminology. In addition, it highlights features omitted from the problem and left to the respondents' imagination. The year begins at time $t=0$, with Alice and Carolyn both having $\$ 10,000$ and ends at time $t=2$, with the women again having $\$ 10,000$. The midyear update is given at time $t=1$ (denoted $1_{\mathrm{A}}$ and $1_{\mathrm{C}}$ for Alice and Carolyn, respectively), and the money possessed by Alice and Carolyn at time $t_{\mathrm{i}}$ (and shown on the ordinate) is $\mathrm{A}_{\mathrm{i}}$ and $\mathrm{C}_{\mathrm{i}}$, respectively. These cumulative earnings will be referred to as "positions" at time $\mathrm{i}$. The dashed lines are possible trajectories. 
We venture to predict that you, the reader, know which woman is happier. Yet, no matter which answer seems "obvious," there are theoretical models to support the other two.

\section{"They Are Equally Happy"}

Perhaps the most straight forward prediction is that made by microeconomic theory: Alice and Carolyn should have equal utility by virtue of the fact that their final positions are identical. They both possess $\$ 10,000$ at year's end. Given the assumptions discussed earlier, both women are equally poised to face the upcoming year's financial travails. To the extent that their trajectories provide no insights about future performance, past information should be ignored (Marshall \& Oliver, 1995). Financial equality would imply equal pleasure, as follows:

$$
\mathrm{A}_{2}=\mathrm{C}_{2} \Rightarrow \mathrm{P}\left(\mathrm{A}_{2}\right)=\mathrm{P}\left(\mathrm{C}_{2}\right)
$$

where $\mathrm{P}\left(\mathrm{A}_{2}\right)$ and $\mathrm{P}\left(\mathrm{C}_{2}\right)$ refer to the pleasure that Alice and Carolyn feel at time $t_{2}$.

Although simple and parsimonious, this argument overlooks the role of reference points (Kahneman \& Tversky, 1979). The status quo is one obvious reference point, and in a dynamic context, it could be defined as the initial financial position. This analysis defines an individual's happiness or pleasure as some function, $f$, of the difference between starting and ending positions, as follows:

$$
f\left(\mathrm{~A}_{2}-\mathrm{A}_{0}\right)=f\left(\mathrm{C}_{2}-\mathrm{C}_{0}\right) \Rightarrow \mathrm{P}\left(\mathrm{A}_{2}\right)=\mathrm{P}\left(\mathrm{C}_{2}\right) .
$$

In short, both hypotheses support the claim that Carolyn and Alice are equally happy. The first hypothesis is insensitive to reference points and states that happiness simply reflects financial positions. The second asserts that pleasure is a comparison between starting and ending positions.

\section{"Carolyn is Happier"}

The question, "Which woman is happier?" requires a comparison of Alice and Carolyn's financial paths. Although the problem provides few details, the single midyear points are strikingly salient. Suppose respondents thought the financial paths between points took the forms shown in Fig. 1. If so, then Carolyn would have at least as much money as Alice at every point in time throughout the year. In this dynamic context, pleasure might be a function of an individual's immediate happiness and happiness experienced in the recent past. For example, happiness might be a weighted average of the present experience and a set of past experiences (i.e., a running window). A simple version of this account for Alice and Carolyn 
could be an average of present and past experiences:

$$
f\left[w \cdot \mathrm{A}_{2}+(1-w) \cdot \mathrm{A}_{1}\right]<f\left[w \cdot \mathrm{C}_{2}+(1-w) \cdot \mathrm{C}_{1}\right] \Rightarrow \mathrm{P}\left(\mathrm{A}_{2}\right)<\mathrm{P}\left(\mathrm{C}_{2}\right)
$$

where $w$ is a weight attached to the present experience. If $w$ is the same for Alice and Carolyn, $\mathrm{A}_{2}=\mathrm{C}_{2}$, and $\mathrm{A}_{1}<\mathrm{C}_{1}$, Carolyn should be happier than Alice at the end of the year.

\section{"Alice is Happier"}

Another way to assess happiness in a dynamic context is to compare one's present experience to prior experiences. From this perspective, happiness would still depend on the past (i.e., the running window), but past experiences would be contrasted to - not assimilated with—the immediate experience. Carolyn's portfolio grew to $\$ 15,000$ and Alice's fell to $\$ 5,000$. Respondents who contrasted those reference points with the year-end position of $\$ 10,000$ would view Carolyn's position as a loss and Alice's position as a gain. This account could be a weighted average of the present experience and a contrast of the present with the past:

$$
\begin{aligned}
& f\left[w \cdot \mathrm{A}_{2}+(1-w) \cdot g\left(\mathrm{~A}_{2}-\mathrm{A}_{1}\right)\right] \\
& \quad<f\left[w \cdot \mathrm{C}_{2}+(1-w) \cdot g\left(\mathrm{C}_{2}-\mathrm{C}_{1}\right)\right] \Rightarrow \mathrm{P}\left(\mathrm{A}_{2}\right)<\mathrm{P}\left(\mathrm{C}_{2}\right)
\end{aligned}
$$

where $g$ is a function of the difference between present and past earnings. For Alice, $g\left(\mathrm{~A}_{2}-\mathrm{A}_{1}\right)>0$, and for Carolyn, $g\left(\mathrm{C}_{2}-\mathrm{C}_{1}\right)<0$. By this account, Alice should be happier than Carolyn.

This contrast theory is consistent with past research showing that people typically prefer and enjoy increasing sequences of positive outcomes (Loewenstein \& Prelec, 1993; Ross \& Simonson, 1991; Varey \& Kahneman, 1992). Furthermore, this account has direct empirical support. The majority of our participants $(71 \%)$ thought that Alice was, indeed, happier than Carolyn.

\section{Multiple Reference Points}

What would these theories predict about the ongoing happiness of the women given more detailed information about their financial paths? To what extent, and in what ways, might we see path dependence? In its simplest guise, path dependence means that where we are today is a function of where we were yesterday. ${ }^{5}$ Of course, the day before yesterday and even the day before that could make a difference. For

\footnotetext{
${ }^{5}$ For the purposes of this paper we are using "path dependence" in this general sense rather than to represent any particular underlying process (e.g. auto-regression, random walk).
} 

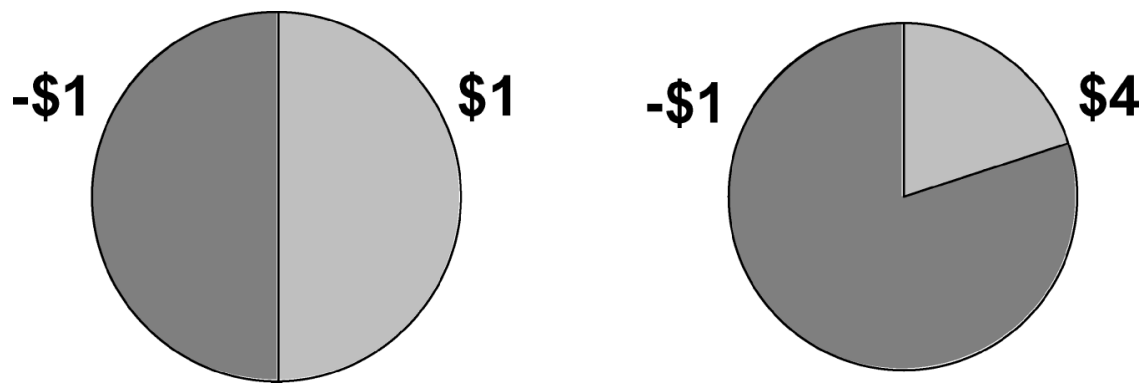

Fig. 2. Example of a gamble pair presented to participants. One outcome, in this case, $-\$ 1$, is common to both gambles in this pair and every other pair.

Alice and Carolyn, year-end happiness could be a function of final positions, the recent past, or even the entire path.

Now let's add another twist. What happens when the information about each woman's financial path includes specific, immediate outcomes? Suppose that Alice's investments went down to $\$ 5,000$ and slowly increased to $\$ 11,000$. On the last day of the year, Alice lost $\$ 1,000$, and her final position was $\$ 10,000$. Carolyn's investments went up to $\$ 15,000$, and gradually fell to $\$ 9,000$. On the last day, Carolyn gained $\$ 1,000$, and her final position was also $\$ 10,000$. Now who is happier?

We devised a task to explore this question. Participants sat at a computer and made a series of choices between binary gambles. Gambles were displayed as pie charts, as shown in Fig. 2, with amounts on any trial ranging from \$4 wins to $\$ 4$ losses. After participants selected the gamble they preferred to play, the unchosen gamble disappeared, and a pointer appeared in the center of the chosen gamble. The pointer spun for a few seconds and eventually stopped, at which point participants learned their outcome. This amount was added to or subtracted from their overall earnings. Cumulative earnings were constantly displayed in the center of the computer screen and were continually updated. Then participants rated the pleasure or displeasure they felt with the outcome on a category rating scale.

There were two groups of participants, each of which took a different trajectory of overall earnings. One went up to $\$ 24$ then back down again, whereas the other went down to $-\$ 24$ and gradually back up again. To control these financial paths, we constructed gamble pairs such that each gamble in a pair had one common outcome. Regardless of the gamble they chose, participants received that outcome. For example, in Fig. 2, the common outcome is $-\$ 1$. Whenever this pair of gambles appeared, the spinner stopped at $-\$ 1$, and participants lost one dollar. The presence of a common outcome was downplayed by randomizing the order of outcomes both within and across gambles. In this way, overall earnings were always under the control of the experimenter and could be manipulated across groups.

Figure 3 shows the financial paths on each trial for the two groups. In the "positive" path, earnings went up then back down to $\$ 0$. In the "negative" path, 


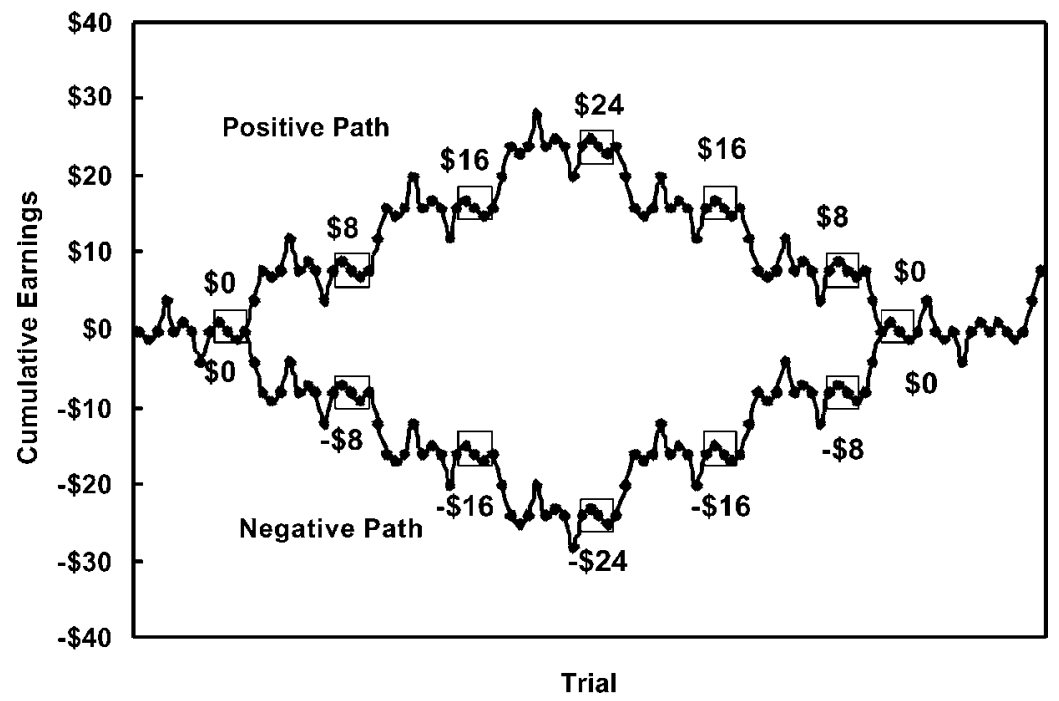

Fig. 3. Cumulative earnings for two groups are plotted against trials. The boxes represent the four gamble pairs with outcomes of $\$ 1$ or $-\$ 1$ that were presented at seven points in each path. Those points occurred when earnings were $\$ 0, \$ 8, \$ 16, \$ 24, \$ 16, \$ 8$, and $\$ 0$ in the positive path, and $\$ 0,-\$ 8,-\$ 16,-\$ 24,-\$ 16,-\$ 8$, and $\$ 0$ in the negative path.

earnings declined and then slowly returned to $\$ 0$. Each path had seven points, highlighted with boxes, where four gamble pairs were presented to the participants. In the positive path, the gamble pairs appeared when cumulative earnings were $\$ 0$, $\$ 8, \$ 16, \$ 24, \$ 16, \$ 8$, and $\$ 0$. In the negative path, the gamble pairs were presented when cumulative earnings were $\$ 0,-\$ 8,-\$ 16,-\$ 24,-\$ 16,-\$ 8$, and $\$ 0$.

The gamble pairs that were repeated in each path allowed us to explore the effects of outcomes and counterfactual outcomes on judged pleasure. They are shown in Table I. The notation, $(\$ 1, .5 ; \$ 4)$, refers to a gamble with a $50 \%$ chance of $\$ 1$, otherwise $\$ 4$, and the bold outcome is the common outcome. Gambles on the left side of each pair constitute a factorial design of outcomes ( $\$ 1$ or $-\$ 1)$ by counterfactual outcomes $(\$ 4$ by $-\$ 4)$. We wanted participants to select the gamble

Table I. Four Gamble Pairs Presented at Seven Points in Each Sequence

T1: $(\$ 1,0.5 ;-\$ 4)$ vs. $(\$ 1,0.2 ;-\$ 4)$

T2: $(-\$ 1,0.5 ; \$ 4)$ vs. $(-\$ 1,0,8 ; \$ 1)$

T3: $(-\$ 1,0.5 ;-\$ 4)$ vs. $(-\$ 1,0.2 ;-\$ 4)$

T4.: (\$1, 0.5; \$4) vs. $(\$ 1,0.8 ;-\$ 4)$

Note. For each pair, the common outcome is highlighted in bold. Gambles on the left were usually more desirable than those on the right. 
on the left, so we made the gamble on the right less appealing. The left-hand gamble dominates the right-hand gamble in pair \#4 and stochastically dominates the righthand gamble in pairs \#1 and \#3. It is the emotional reactions to these outcomes (\$1 or $-\$ 1$ ) with two possible counterfactual outcomes $(\$ 4$ or $-\$ 4)$ that will be the focus of our discussion.

If the results from the first story about Alice and Carolyn generalize to this task, we would expect participants in the negative path to be happier than participants in the positive path when cumulative earnings returned to $\$ 0$. The contrast theory we described above is similar to an account of outcome satisfaction offered by (Hsee \& Abelson, 1991) and (Hsee, Abelson, \& Salovey, 1991). Outcome satisfaction, they claim, is an average of position and velocity-the rate of change between one position and another. Higher positions and faster rates of positive change lead to greater outcome satisfaction. Our account and that proposed by Hsee et al. (1991) are not identical because contrasts differ from velocities. A contrast is a directional change in position, whereas velocity refers to a directional change in positions over a fixed time interval (Hsee et al., 1991). In more recent work, (Hsee, Salovey, \& Abelson, 1994) introduced a third factor. They included acceleration or the rate at which velocities change over a fixed time interval. We will not be discussing that theory here.

\section{Immediate Reference Points}

A common finding in the literature on consumer choice is that people lack stable preferences and construct them whenever necessary (see (Bettman, Luce, \& Payne, 1998) for an overview). Constructed preferences depend on option framing (Levin \& Gaeth, 1988), task characteristics (Nowlis \& Simonson, 1997; Tversky, Sattath, \& Slovic, 1988), context (Huber, Payne, \& Puto, 1982; Simonson \& Tversky, 1992) and reference points (Winer, 1986). Satisfaction, like choice, is also frequently constructed.

One account of outcome satisfaction and pleasure is decision affect theory (Mellers, 2000). The pleasure of an outcome depends on the utility or satisfaction of the outcome, comparisons between obtained and counterfactual outcomes, and the strength of beliefs about what might have occurred. Decision affect theory explains why, in gambling contexts, people may derive greater pleasure or satisfaction from a smaller win than a larger win, and less pain from a larger loss than a smaller loss. In fact, people may derive greater pleasure from a loss than from a gain, depending on the counterfactual outcomes (Mellers, Schwartz, \& Ritov, 1999).

\section{Immediate versus Background Reference Points}

How do immediate reference points in the foreground interact with ongoing reference points in the background? It is hard to know, and the complexity 
of this question for our experiment becomes clear when one considers the variety of ways a participant could interpret the instructions to "Rate your pleasure with this outcome." "Outcome" could refer to the most recent win or loss or to the cumulative earnings. Let's assume that a participant focuses on an immediate outcome. He or she is on the downward trend of the positive path when, already being up $\$ 16$, he wins $\$ 1$ instead of $\$ 4$. Perhaps the simplest interpretation would be to compare the $\$ 1$ to the status quo; winning $\$ 1$ is surely better than winning nothing. An alternative comparison is between $\$ 1$ and the counterfactual outcome of $\$ 4$; in this case, the $\$ 1$ outcome may not feel so good. Moreover, if the newly won dollar is compared to the cumulative earnings of $\$ 16$, it might hardly be noticed. It is a very small contribution to the overall winnings. In short, the pleasure of any given "outcome" could be interpreted in numerous ways.

Are there any psychological reasons why some reference points would be more salient than others? In our task, the salience of a reference point may depend on memory load and cognitive effort. Consider the reference points described earlier. The actual outcome and the counterfactual outcome presumably reside in short term or even iconic memory. It is easy to use these reference points. Even though one's cumulative earnings are continuously displayed on the screen, they are unlikely to garner as much attention as the spinner. For this reason, they would require additional effort. Likewise, trends or velocities in cumulative earnings would require the retrieval of even more information from long-term memory and presumably more cognitive effort. Increasingly complex forms of path dependency, such as acceleration, increase the effort. For this reason, we expect position (cumulative earnings) and contrast (comparison with some set of previous earnings) to have less of an impact on pleasure than outcomes or counterfactual outcomes.

\section{METHOD}

\section{Participants}

Seventy-five undergraduates at Ohio State University served as participants in the experiment (38 and 37 in the group with a positive path and negative path, respectively). They were recruited after reading an advertisement in the campus paper and contacting us to participate.

\section{Instructions and Procedure}

Participants were told they would be paid whatever they earned over the course of the experiment. To encourage participation, they were informed that average earnings were approximately $\$ 8$. However, there was a small chance they could win or lose as much as $\$ 40$. In the unlikely event that they lost money, they 
would be asked to work it off in the Decision Making laboratory at a rate of $\$ 10$ an hour doing menial jobs, such as filing papers or entering data in the computer. These instructions were necessary to make participants believe that both wins and losses were real. The experiment included a few practice trials, followed by 100 experimental trials (given in the Appendix). On each trial, participants made a choice, then rated their pleasure or displeasure with the outcome on a category rating scale from $50=$ extremely elated to $-50=$ extremely disappointed.

After the 100 experimental trials, we added a few more trials to probabilistically adjust each individual's payment to an amount ranging from $\$ 6$ to $\$ 10$. Average payments were \$8. Finally, participants were given a brief follow-up questionnaire that probed their beliefs about the study. Seven respondents indicated some degree of suspicion. We excluded those participants, as well as six others who did not follow the instructions. The remaining 62 participants were used in the analyses.

\section{RESULTS}

We were especially interested in the emotional responses to the four outcomes of the left-hand gambles in Table 1, when presented in each path. When computing the average emotional responses, we only included a response if participants had selected the left-hand gamble. If participants selected the right-hand gamble, their ratings were omitted from the analysis. These omissions created no serious problems because the left-hand gamble was selected from the sets of four gambles in $98 \%$ of the cases. The solid lines in Fig. 4 shows emotional responses, averaged over $\$ 1$ wins and \$1 losses against cumulative earnings, with separate curves for each path. Recall that cumulative earnings were $\$ 0, \$ 8, \$ 16, \$ 24, \$ 16, \$ 8$, and $\$ 0$ in the positive path and $\$ 0,-\$ 8,-\$ 16,-\$ 24,-\$ 16,-\$ 8$, and $\$ 0$ in the negative path. Dashed lines are predictions of decision affect theory and will be discussed in more detail later.

If there were background effects of positions and trends, they would be apparent in Fig. 4. The pleasure of wins and losses generally tracks cumulative earnings; participants in the positive path felt greater pleasure with their outcomes than participants in the negative path, except at the final point when cumulative earnings returned to $\$ 0$. At that point, participants in the negative path were actually happier with their outcomes than those in the positive path, as expected from the Alice and Carolyn story. In sum, we find evidence of background positions and background trends, even when detailed information about outcomes and counterfactual outcomes is provided. An analysis of variance revealed a significant main effect of path, $F(1,11)=5.88 .^{6}$ The interaction between path and cumulative earnings, $F(6,66)=2.84$, was also significant. In summary, background reference points

${ }^{6}$ Alpha was set to .05 was used for all statistical tests. 


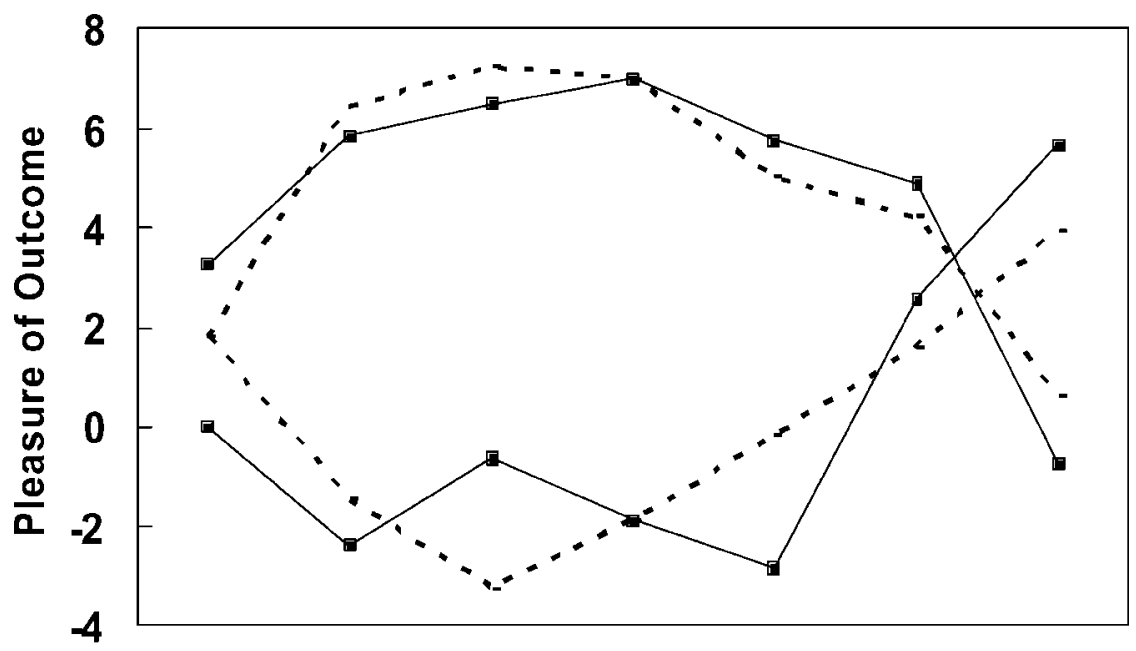

\section{Cumulative Earnings}

Fig. 4. Solid lines show the average pleasure of $\$ 1$ and $-\$ 1$ (when the unobtained outcome was either $\$ 4$ or $-\$ 4)$ at each of the seven points in both paths. Dashed lines show predictions of an extended form of decision affect theory.

influence the pleasure of outcomes, even when foreground reference points are salient.

The solid lines in Fig. 5 show the effects of obtained outcomes and counterfactual outcomes. Dashed lines are predictions that will be discussed later. Average pleasure is plotted against outcomes with separate curves for unobtained outcomes and separate panels for each path. Pleasure increased with the outcome, $F(1,11)=$ 30.17 , and pleasure decreased with the counterfactual outcome. Outcomes feel better when "what might have been" is worse, not better, than what actually occurred, $F(1,11)=22.85$.

What is puzzling about Fig. 5 is why counterfactual outcomes, which have no material effects on outcomes or cumulative earnings, are so important in judgments of pleasure. In the positive path on the left, the average feeling associated with a $\$ 1$ loss is " 6 " when the counterfactual outcome is $-\$ 4$. That average feeling is very similar to " 8 ," the feeling associated with a $\$ 1$ gain when the counterfactual outcome is $\$ 4$. The feeling of a gain is similar to that of a loss. Furthermore, these responses were comparable at all seven points in time for both paths. In sum, Figure 5 shows the powerful effects of immediate reference points on judgments of pleasure.

To compare the relative contributions of background and foreground reference points on affective experiences, we performed multiple regressions on the individual responses to outcomes in the positive and negative paths. In each group, 


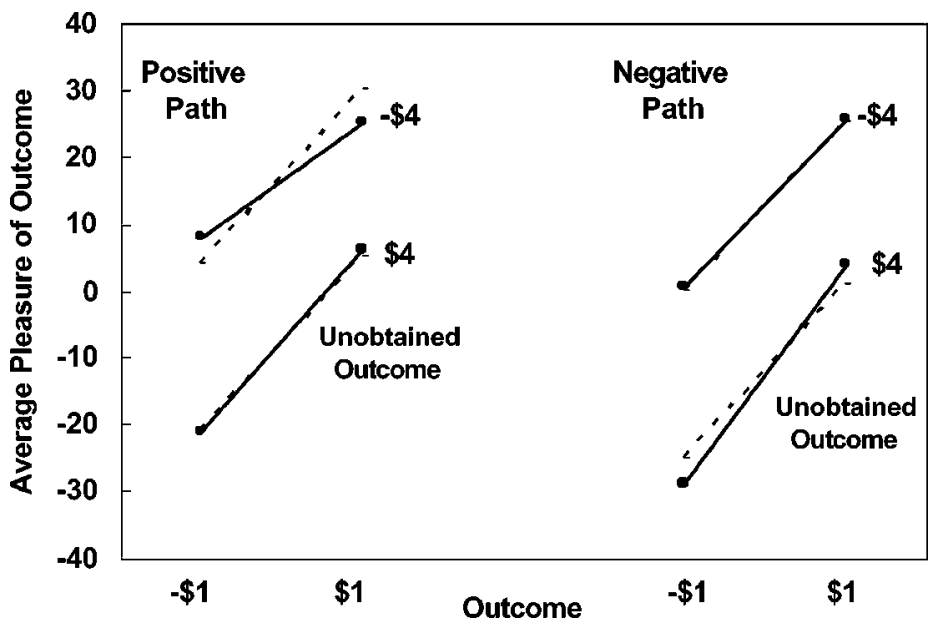

Fig. 5. Solid lines show the pleasure of outcomes $(\$ 1$ and $-\$ 1)$ with separate curves for unobtained outcomes ( $\$ 4$ and $-\$ 4$ ). Results are presented from the positive and negative paths on the left and right, respectively. This pattern held across all seven points in both sequences. Dashed lines are predictions of decision affect theory.

we predicted the pleasure of the four outcomes presented at seven points in time from (1) outcome, (2) counterfactual outcome, (3) cumulative earnings (or position), and (4) trend. The beta weights from these multiple regressions give us some notion about the impact of immediate and ongoing reference points.

In the positive path, the beta weight for obtained outcomes was .43. Beta weights for counterfactual outcomes, earnings, and trends were $-.47, .06$, and .04, respectively. Counterfactual outcomes and obtained outcomes had comparable impacts. The weights associated with earnings and trends were much smaller; their contributions were relatively weaker. Similar results were found with the negative path. The beta weight for obtained outcomes was .51, and weights for counterfactual outcomes, earnings, and trends were $-.45, .06$, and .03 , respectively. The immediate context dominates the background context. Furthermore, the effect of counterfactual outcomes, which has nothing to do with take-home pay, is similar in magnitude to that of the actual outcome.

\section{Decision Affect Theory}

As mentioned earlier, decision affect theory predicts outcome pleasure as a function of immediate reference points and immediate beliefs. To illustrate, consider a choice between two gambles. Gamble 1 has two outcomes, $w$ and $x$. Gamble 2 has two outcomes, $y$ and $z$. Suppose a decision maker chooses Gamble 1, 
and outcome $w$ occurs. Decision affect theory is expressed as:

$$
\mathrm{P}(w)=J[\mathrm{u}(w)+d[\mathrm{u}(w)-\mathrm{u}(x)] \cdot[1-\mathrm{s}(w)]],
$$

where $\mathrm{P}(w)$ is the pleasure of outcome $w, J$ is a response function that takes a feeling to a numerical rating, $\mathrm{u}(w)$ is the utility of outcome $w, d[\mathrm{u}(w)-\mathbf{u}(x)]$ is a disappointment function that reflects the comparison between what actually occurred and what might have occurred, and $1-\mathrm{s}(w)$ is the subjective probability that outcome $w$ would not occur (i.e., the surprisingness of $w$ ).

In the form above, decision affect theory predicts the effects of foreground reference points, but not background reference points. Suppose a decision maker has cumulative earnings, $T$. He chooses Gamble 1 , and outcome $w$ occurs. His total earnings are now $T+w$. We propose that both the utility of the current earnings $u(T+w)$, and a contrast between present and previous earnings are salient. This contrast will be written as some function, $f$, of the difference between the utility of present earnings and the utility of some set of past earnings, or $f[u(T+w)-$ $\left.u\left(T_{\mathrm{P}}\right)\right]$.

Taken together, the pleasure of outcome $w$ can be expressed:

$$
\mathrm{P}(w)=J\left[u(w)+d[u(w)-u(x)]+u(T+w)+f\left[u(T+w)-u\left(T_{\mathrm{P}}\right)\right]\right] .
$$

This form of decision affect theory, like Hsee et al.'s theory, includes terms for position and trend. In this experiment, trend (or contrast) is similar to velocity. However, decision affect theory, unlike Hsee et al.'s theory, includes information about the immediate outcome and counterfactual outcomes. According to decision affect theory, at any moment in time, outcome pleasure and satisfaction depend on both categories of reference points.

To fit this form of decision affect theory to the data, we used Solver, a feature in Microsoft's Excel program, to find parameters that minimized the proportion of squared errors between data and predictions of the theory. We assumed that the utilities of the two outcomes and the values representing the disappointment function were identical across sequences. We estimated the utility of $\$ 1$, and fixed the utility of $-\$ 1$ to -1 . The disappointment function was represented as a step function, and step sizes could differ for positive and negative comparisons. We estimated the parameter for positive comparisons and fixed the parameter for negative comparisons to -4 . In previous formulations of decision affect theory, the disappointment function was weighted by the surprisingness of the outcome, but in this experiment, the probability of all outcomes was 0.5 . Therefore, surprise was confounded with (and included within) the disappointment function.

To describe background effects, we estimated parameters for position and trend (or contrast). We estimated a position value for $\$ 0$ that was assumed to be the same across paths. We also estimated three unique positions for each path (i.e., values corresponding to $\$ 8, \$ 16$, and $\$ 24$ for the positive path and values corresponding to $-\$ 8,-\$ 16$, and $-\$ 24$ for the negative path). Finally, we allowed 


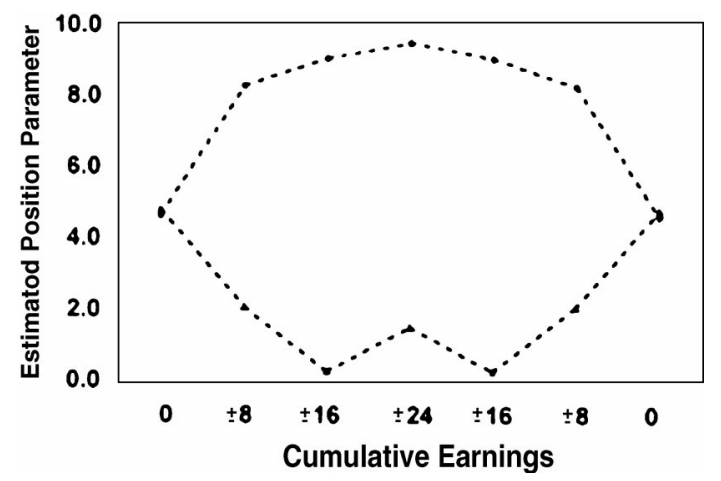

Fig. 6. Estimated position parameters for each sequence. Values generally track cumulative earnings.

four contrast parameters (values that represented either upward or downward trends in each path). We fixed the upward trend in the positive path to 1.0 and the downward trend in the negative path to -1.0 and estimated the other two trends. (Notice that this form of the theory is insensitive to the length of time the upward or downward trend has occurred.) This version of decision affect theory required 11 parameters to describe the 56 mean judgments.

Predictions are shown as dashed lines in Figs. 4 and 5. Decision affect theory captures the fact that participants in the negative path were happier than participants in the positive path when the cumulative earnings returned to $\$ 0$ (Fig. 4). The theory also describes the finding that gains and losses can be equally pleasurable, depending on counterfactual outcomes (Fig. 5).

The predictions left less than $5 \%$ of residual variance remaining in the mean judgments. Values of the utilities for $\$ 1$ and $-\$ 1$ were 1 and -25 , respectively. Positive and negative step sizes from the disappointment function were 21 and -4 , respectively. Values of position corresponding to $-\$ 24,-\$ 16,-\$ 8$ and $\$ 0$ (from the negative path) and $\$ 0, \$ 8, \$ 16$, and $\$ 24$ (from the positive path) are shown in Fig. 6. These parameters tend to track cumulative earnings, with only a few minor deviations.

Trend parameters show an interesting pattern. In the positive path, the upward and downward trends were 1.0 and -1.2 , respectively. These values were relatively similar. However, in the negative path, the upward and downwards were -1.0 and 2.1 , respectively. In the negative path, the upward trend had a bigger effect than the downward trend. A comparison of trends across paths shows that downward trends were similar in magnitude. It feels just as bad to be on a losing streak that started at \$24 than one that started at \$0. However, upward trends differed across paths. The upward trend in the negative path was twice as large as the upward trend in the positive path. Participants felt much better to be on a winning streak that started at $-\$ 24$ than one that started at $\$ 0$. 
We fit decision affect theory to individuals as well as means. There were 7 estimated parameters for each participant, including one trend term, four position parameters, one utility, and one value of the disappointment function. Fits were reasonable for the majority of individuals. In the negative path, the residual variance ranged from $4 \%$ to $63 \%$, with a median value of $27 \%$. The impact of an upward trend was greater than that of a downward trend for the majority of participants. The median upward trend was 3.3, relative to a fixed downward trend of -1.0 .

In the positive path, the residual variance ranged from 6 to $62 \%$, with a median value of $23 \%$. The impact of the downward trend was similar to that of the upward trend for the majority of individuals. The median downward trend was -1.2 , relative to the fixed upward trend of 1.0 . In sum, the means provide an accurate reflection of the vast majority of individuals.

\section{DISCUSSION}

The human sensory system is largely tuned to change. Our judgments and evaluations typically involve comparisons of outcomes and experiences to reference points. Reference points are so engrained in our evaluations that, in their absence, we either find them or manufacture them. But that is rarely the case; we usually have an abundance of reference points from which to choose right at our fingertips.

In this study, we examine whether background reference points (i.e., cumulative earnings and trends in earnings) continue to influence pleasure in the face of immediate reference points (i.e., counterfactual outcomes). Both background and foreground reference points determine the satisfaction and pleasure of outcomes. Evidence for background reference points can be seen in Fig. 4. Participants whose cumulative earnings started at $\$ 0$, went up to $\$ 24$, then returned to $\$ 0$ felt worse about $\$ 1$ wins and $\$ 1$ losses when their earnings returned to $\$ 0$ than did participants who started at $\$ 0$, went down to $-\$ 24$, then returned to $\$ 0$ again. Background effects were reasonably well summarized in terms of position and trends, however positions interact with trends. Being on a winning streak had greater affective impact after losing \$24 than after losing \$0. Participants may have felt both pleasure and "relief" when it seemed they might recoup their losses.

Evidence of foreground reference points can be seen in Fig. 5. This figure shows that, holding all else constant, participants experience greater pleasure with a \$1 win than a \$1 loss. But because the outcomes were also compared to "what might have occurred," the pleasure of a $\$ 1$ win that could have been better $(\$ 4)$ win was comparable to the pain of a $\$ 1$ loss that could have been worse $(-\$ 4)$.

When decision affect theory is extended with additional components that reflect position and trend, it provides a good summary of the results. It predicts the effects of the background (see dashed lines in Fig. 4), and it predicts the effects of the counterfactual outcome (see dashed lines in Fig. 5). The utility of outcomes 
and the disappointment function did not differ across paths, but the psychological impact of the trend depended on position.

What about the relative impact of the background and foreground reference points? Our results suggest that immediate reference points have a greater impact than background reference points on the pleasure of outcomes. There are many situations in which people narrow their attention to the immediate context in a myopic fashion. The satisfaction of an employee who learns his or her annual raise is virtually uninfluenced by current level of salary (Rambo \& Pinto, 1989; Worley, Bowen, \& Lawler, 1992). A student's affective response to a final grade is probably independent of his or her overall grade point average. Even addictions to alcohol or drugs might be viewed in terms of the relative impact of reference points. Visceral drives, such as hunger, thirst, and sexual desire are immediate needs that "crowd out" all other goals or reference points (Loewenstein, 1996).

Other evidence of myopia can be found in the literature on affective forecasting. Kahneman (1999) argues that, when making affective forecasts, we tend to neglect the likelihood of adaptation and overweight our immediate feelings. That is why most of us are surprised to learn that lottery winners are only slightly happier than controls, and controls are only mildly happier than paraplegics. Furthermore, immediate feelings have a disproportionate effect on memories of past feelings. Extreme initial feelings that soften over time are often remembered as softer initially. For example, (Levine, 1997) investigated the emotions of Ross Perot supporters in the 1992 election in July, when he withdrew from the election for 3 months, and again in November, when he lost. At both occasions, supporters were asked how they felt about Perot. In November, supporters were also asked to recall their feelings in July. Those who were angry or sad in July remembered themselves as being less angry or sad than they had actually reported.

Myopia could also have the opposite effect. Soft initial feelings that become more extreme over time may be remembered as extreme initially. McFarland and Ross (1987) measured the romantic feelings of couples at the beginning of their relationship and two months later. Those whose feelings soured over time recalled their initial feelings as more negative than they had actually reported, whereas those whose feelings blossomed over time recalled their initial feelings as being more positive than they had reported.

Myopia occurs in choices as well as emotions (Strotz, 1955). When making choices over time, people are very sensitive to short time delays, but relatively insensitive to the same delay in the distant future (see Loewenstein \& Elster, 1992, for a review). Myopic choices are also be manifested in terms of the frequency with which decision makers evaluate the consequences of their choices. The equity premium puzzle Benartzi and Thaler (1995) refers to the empirical fact that stocks have outperformed bonds over the last century by a surprising margin, yet people still invest heavily in bonds. Benartzi and Thaler argue that the puzzle can be explained if investors are (1) loss averse (i.e., they have greater sensitivity to losses than 


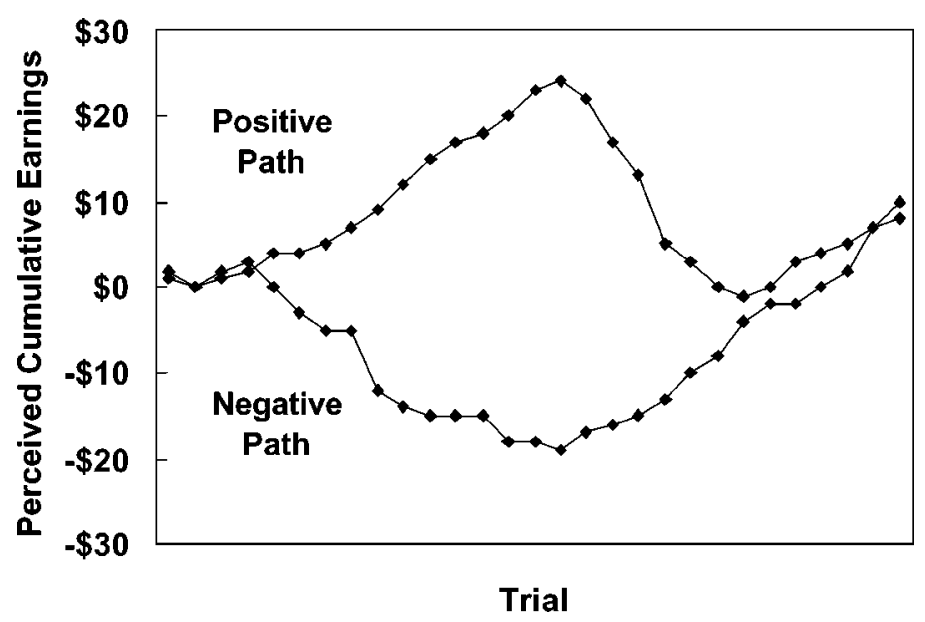

Fig. 7. Average curves of remembered earnings obtained during post experimental interviews for participants in the positive and negative paths.

equivalent gains) and (2) myopic (i.e., they evaluate their portfolios too frequently given their desire for long-term gains and their sensitivity to immediate losses). Myopic loss aversion makes bonds seem more attractive and stocks seem overly risky.

\section{Limitations}

The modified version of decision affect theory that we propose gives less than a complete account of outcome pleasure. People may not be fully cognizant of the reference points they use, and our arbitrary starting points to define trends is problematic. ${ }^{7}$ Furthermore, we have ignored "momentum" variables that would increase a trend's impact as a function of the length of time the trend has been occurring (e.g., Hsee et al., 1994). This information would require greater cognitive effort to retrieve from memory. During the postexperiment debriefing, we asked participants to draw a curve of their cumulative earnings during the course of the experiment. Average curves are show in Fig. 7. All of the participants correctly judged the general trajectory of their earnings, and most correctly remembered their winning and losing.

The most interesting implication of Fig. 7 is that it rules out the possibility that background reference points played a weaker role than immediate reference points because participants couldn't remember the sequence. If participants had wanted background reference points to have a greater influence, they certainly could have; participants clearly had access to that information in memory. Why wasn't it more

${ }^{7}$ Our model shares this problem of arbitrary initial points with Hsee et al's model. 
salient? We suspect the answer lies in the recency of immediate reference points and the cognitive effort required to use background reference points.

What are the implications of our results for consumer satisfaction? In our experiment, pleasure depends on foreground and background reference points, though immediate anchors dominate ongoing anchors. In the context of consumer choice, ongoing prices might serve as background reference points. Decreasing prices are appealing, but decreasing prices might not might not make up for a negative comparison in the foreground. An unappealing package, an undesirable feature, or an attractive competitor could overwhelm the positive effects of the background sequence. On the flip side, increasing prices might seem less painful in light of a new, eye-catching label or a coupon for future discounts. Consumers may show much less sensitivity to changes in ongoing, background information.

Finally, let's return to Alice. Was Alice really happier than Carolyn at the end of the year? Although her net results are no better than Carolyn's, the absence of any negative reference points in the immediate context, the positive trend at the end of the year, and the sense of relief that comes with recouping one's losses should combine to make Alice happier than Carolyn. Despite her enjoyment of superior results throughout the year, Carolyn may be the one looking for a new stockbroker.

\section{APPENDIX}

To describe the two sequences of 100 gamble pairs used in our experiment, we first define the individual pairs. The first four pairs, T1, T2, T3, and T4, are shown in Table I. Six additional gamble pairs had a common win, W1, W2, W3, $\mathrm{W} 4, \mathrm{~W} 5$, and $\mathrm{W} 6$, where $\mathrm{W} 1=[(\mathbf{\$ 4}, 0.8 ;-\$ 1),(\mathbf{\$ 4}, 0.5 ; \$ 1)], \mathrm{W} 2=[(\mathbf{\$ 4}, 0.8$; $-\$ 1),(\$ 4,0.2 ; \$ 1)], \mathrm{W} 3=[(\$ 4,0.8 ;-\$ 4),(\$ 4,0.5 ;-\$ 1)], \mathrm{W} 4=[(\$ 4,0.8 ;-\$ 4)$, $(\$ 4,0.2 ;-\$ 1)], \mathrm{W} 5=[(\mathbf{\$ 1}, 0.8 ;-\$ 4),(\$ 1,0.2 ;-\$ 1)]$, and $\mathrm{W} 6=[(\mathbf{\$ 1}, 0.8 ;-\$ 4)$, $(\$ 1,0.5 ;-\$ 1)]$. Three additional gamble pairs had a common loss, L1, L2, and L3, where L1 $=[(-\$ 1,0.5 ;-\$ 4),(\$ 4,0.2 ;-\$ 4)], \mathrm{L} 2=[(-\$ 1,0.8 ;-\$ 1),(\$ 4$, $0.5 ;-\$ 1)]$, and L3 $=[(-\$ 1,0.8 ;-\$ 4),(\$ 4,0.5 ;-\$ 4)]$.

Now, we define four sets. Set $1=\{\mathrm{L} 2, \mathrm{~W} 5, \mathrm{~W} 1, \mathrm{~L} 1, \mathrm{~T} 2, \mathrm{~W} 6, \mathrm{~L} 3, \mathrm{~W} 2, \mathrm{~T} 1$, T2, T3, T4 $\}$, Set $2=\{\mathrm{W} 3, \mathrm{~W} 4\}$, Set $3=\{\mathrm{L} 1, \mathrm{~L} 3\}$, and Set $4=\{\mathrm{T} 1, \mathrm{~T} 2, \mathrm{~T} 3, \mathrm{~T} 4$, W1, L1, T2, W5, L3, W2, W6, L2, T1, T2, T3, T4\}.

Finally, we define the sequences in terms of sets. The positive sequence was Set 1, Set 2, Set 1, Set 2, Set 1, Set 2, Set 1, Set 3, Set 1, Set 3, Set 1, Set 3, and Set 4. The negative sequence was Set 1, Set 3, Set 1, Set 3, Set 1, Set 3, Set 1, Set 2, Set 1, Set 2, Set 1, Set 2 and Set 4.

\section{REFERENCES}

Benartzi, S., \& Thaler, R. H. (1995). Myopic loss aversion and the equity premium puzzle. Quarterly Journal of Economics, 110 (February), 73-92. 
Bettman, J. R., Luce, M. F., \& Payne, J. W. (1998). Constructive consumer choice processes. Journal of Consumer Research, 25(3), 187-217.

Boulding, W., Kalra, A., Staelin, R., \& Zeithaml, V. (1993). A dynamic process model of service quality: From expectations to behavioral intentions. Journal of Marketing Research, 30, 7-27.

Cadotte, E., Woodruff, R., \& Jenkins, R. (1987). Expectations and norms in models of consumer satisfaction. Journal of Marketing Research, 24, 305-314.

Dabholkar, P. (1994). Does customer satisfaction predict postpurchase intentions? Journal of Consumer Satisfaction, Dissatisfaction, and Complaining Behavior, 7, 161-171.

Erevelles, S., \& Leavitt, C. (1992). A comparison of current models of consumer satisfaction/ dissatisfaction. Journal of Consumer Satisfaction, Dissatisfaction, and Complaining Behavior, $5,104-114$.

Fournier, S., \& Mick, D. (1999). Rediscovering satisfaction. Journal of Marketing, 63(4), 5-19.

Heath, C., Larrick, R. P., \& Wu, G. (1999). Goals as reference points. Cognitive Psychology. Special Issue: Belief and decision: The continuing legacy of Amos Tversky, 38(1), 79-109.

Hsee, C. K., \& Abelson, R. P. (1991). The velocity relation: Satisfaction as a function of the first derivative of outcome over time. Journal of Personality and Social Psychology, 60, 341-347.

Hsee, C. K., Abelson, R. P., \& Salovey, P. (1991). The relative weighting of position and velocity in satisfaction. Psychological Science, 2(4), 263-266.

Hsee, C. K., Salovey, P., \& Abelson, R. P. (1994). The quasi-acceleration relation: Satisfaction as a function of the change of velocity of outcome over time. Journal of Experimental Social Psychology, 30, 96-111.

Huber, J., Payne, J. W., \& Puto, C. (1982). Adding asymmetrically dominated alternatives: Violations of regularity and the similarity hypothesis. Journal of Consumer Research, 9(1), 90-98.

Iacobucci, D., Grayson, K., \& Ostrom, A. (1994). The calculus of service quality and customer satisfaction: Theoretical and empirical differentiation and integration. Advances in Services Marketing and Management, 3, 1-67.

Kahneman, D. (1999). Objective happiness. In D. Kahneman, E. Diener, \& N. Schwarz (Eds.), Wellbeing: The foundations of hedonic psychology (pp. 3-25). New York: Sage.

Kahneman, D., \& Miller, D. T. (1986). Norm theory: Comparing reality to its alternatives. Psychological review, 93(2), 136-153.

Kahneman, D., \& Tversky, A. (1979). Prospect Theory: An analysis of decision under risk. Econometrica, 47, 263-291.

Levin, I. P., \& Gaeth, G. J. (1988). How consumers are affected by the framing of attribute information before and after consuming the product. Journal of Consumer Research, 15(3), 374-378.

Levine, L. J. (1997). Reconstructing memory for emotions. Journal of Experimental Psychology: General, 126(2), 165-177.

Loewenstein, G. (1996). Out of control: Visceral influences on behavior. Organizational Behavior and Human Decision Processes, 65(3), 272-292.

Loewenstein, G., \& Elster, J. (1992). Choice over time. New York, NY: Sage.

Loewenstein, G., \& Prelec, D. (1993). Preferences for sequences of outcomes. Psychological Review, $100(1), 91-108$.

Lopes, L. L. (1987). Between hope and fear: The psychology of risk. In L. Berkowitz (Ed.), Advances in experimental social psychology (Vol. 20, pp. 255-295). San Diego, CA: Academic Press.

Markman, K. D., Gavanski, I., Sherman, S. J., \& McMullen, M. N. (1993). The mental simulation of better and worse possible worlds. Journal of experimental social psychology, 29(1), 87-109.

Marshall, K. T., \& Oliver, R. M. (1995). Decision making and forecasting. New York: McGraw-Hill.

McFarland, C., \& Ross, M. (1987). The relation between current impressions and memories of self and dating partners. Personality and Social Psychology Bulletin, 13(2), 228-238.

Mellers, B. (2000). Choice and the relative pleasure of consequences. Psychological Bulletin, 126, 910-924.

Mellers, B., Schwartz, A., \& Ritov, I. (1999). Emotion-based choice. Journal of Experimental Psychology: General, 128(3), 332-345.

Nowlis, S. M., \& Simonson, I. (1997). Attribute-task compatibility as a determinant of consumer preference reversals. Journal of Marketing Research, 34(2), 205-218.

Oliver, R., \& Swan, J. E. (1989). Consumer perceptions of interpersonal equity and satisfaction in transactions: A field survey approach. Journal of Marketing, 53, 21-35. 
Rambo, W. W., \& Pinto, J. N. (1989). Employees' perception of pay increases. Journal of Occupational Psychology, 62(2), 135-145.

Roese, N. J., \& Olson, J. M. (1995). Counterfactual thinking: A critical overview. In N. J. Roese \& J. M. Olson (Eds.), What might have been: The social psychology of counterfactual thinking (pp. 1-55). Hillsdale, NJ Erlbaum.

Ross, W. T., \& Simonson, I. (1991). Evaluations of pairs of experiences: A preference for happy endings. Journal of Behavioral Decision Making, 4, 273-282.

Simonson, I., \& Tversky, A. (1992). Choice in context: Tradeoff contrast and extremeness aversion. Journal of Marketing Research, 29(3), 281-295.

Strotz, R. H. (1955). Myopia and inconsistency in dynamic utility maximization. Review of Economic Studies, 23, 165-180.

Tesser, A. (1999). Toward a self-evaluation maintenance model of social behavior. In R. Baumeister (Ed.), The self in social psychology (pp. 446-460). Philadelphia, PA: Psychology Press.

Tversky, A., Sattath, S., \& Slovic, P. (1988). Contingent weighting in judgment and choice. Psychological review, 95(3), 371-384.

Varey, C. A., \& Kahneman, D. (1992). Experiences extended across time: Evaluation of moments and episodes. Journal of Behavioral Decision Making, 5(3), 169-185.

Westbrook, R. (1987). Product/consumption-based affective responses and postpurchase processes. Journal of Marketing Research, 24, 258-270.

Winer, R. S. (1986). A reference price model of brand choice for frequently purchased products. Journal of Consumer Research, 13(2), 250-256.

Worley, C. G., Bowen, D. E., \& Lawler, E. E. (1992). On the relationship between objective increases in pay and employees' subjective reactions. Journal of Organizational Behavior, 13(6), 559-571. 